Федерации для эффективного использования потенциала транспортной системы в целях повышения благосостояния общества и государства в целом.

Основные задачи Стратегии:

- повышение конкурентных преимуществ транспортного комплекса;

- снижение транспортных издержек в экономике;

- обеспечение эффективного использования транспорта, его производственная и социальная доступность;

- модернизация современной транспортной системы путем развития частно- государственного партнерства.

При создании и реализации Стратегии и ее приоритетных направлений были проанализированы стратегические установки иностранных государств и учтен зарубежный опыт.

Таким образом, можно сделать вывод, что транспорт представляет собой крупнейшую системообразующую сферу, имеющую тесные связи с экономикой и социальным составляющим. Расширение и развитие внутренних и внешних транспортных сетей привет к улучшению качества жизни населения, увеличению объемов производства и значительно повысит роль транспорта как системообразующей отрасли. Перспективное направление развития транспортной системы должно осуществляться на основе анализа нынешнего состояния транспортного комплекса, социально-экономического развития страны и опыта зарубежных стран. Основная концепция развития транспортной системы в условиях рыночных отношений должна быть направлена на интеграцию принципов рыночной самоорганизации и государственного регулирования всего транспортного процесса.

$$
* * *
$$

1. Вываерц А.Д. Экономика предприятия. М.: Юнити-Дана, 2017 г., 544 с.

2. Латыпова Р.Р. Классификация и виды транспортных рисков // Вестник Северо-Кавказского федерального университета. 2016. № 1 (52). С. 71-76.

3. Проблема развития транспорта в условиях глобализации мирового хозяйства. // Экономические науки. - 2007. - №1., 34 с.

4. Транспортная стратегия Российской Федерации. [Электронный ресурс]: - //- Режим доступа: http://www.mintrans.ru/pressa/TransStrat_Gossovet_Rab_Groop_3.htm (дата обращения 23.10.2019г.)

5. Трубецкой К.Н., Кулешов А.А., Клебанов А.Ф. Современные системы управления транспортным комплексом. М.: Наука, 2015 г., 312 с.

\title{
Балашов А.М.
}

Актуальность инновационного развития экономики РФ в современных условиях

ГОУ ВПО Новосибирский государственный педагогический университет (Россия, Новосибирск)

doi: $10.18411 / \mathrm{j}-10-2019-165$

idsp: ljournal-10-2019-165

\section{Аннотация}

В данной статье автор показывает актуальность и необходимость перехода экономики России к новой модели развития, которая основана на структурной перестройке, модернизации и инновациях. В настоящее время нашей стране необходима неоиндустриализация, которая понимается как качественные изменения в экономике, трансформация производительных сил, переход на информационные технологии, создание современной инфраструктуры, качественно новый уровень образования и медицинского обслуживания. Результатом успешной реализации намеченных программ должно стать усиление конкурентоспособности компаний и российской экономики в целом, устойчивый экономический рост и увеличение благосостояния населения. 


\begin{tabular}{l}
\multicolumn{1}{l}{ Ключевые слова: инновационное } \\
$\begin{array}{l}\text { неоввитие, } \\
\text { экономистриализация, }\end{array}$ \\
$\begin{array}{l}\text { конкурентоспособность, } \\
\text { сбалансированность, }\end{array}$ \\
\end{tabular}

\section{Abstract}

In this article, the author shows the relevance and necessity of the transition of the Russian economy to a new model of development, which is based on structural restructuring, modernization and innovation. Currently, our country needs neo-industrialization, which is understood as qualitative changes in the economy, transformation of productive forces, transition to information technology, creation of modern infrastructure, a qualitatively new level of education and medical care. The result of successful implementation of the planned programs should be strengthening the competitiveness of companies and the Russian economy as a whole, sustainable economic growth and increasing the welfare of the population.

Keywords: innovative development, competitiveness, neo-industrialization, business sector, balance, economic growth.

Переход к инновационному типу экономики и необходимость активного внедрения инноваций в производство в Российской Федерации на протяжении последних лет признан приоритетным направлением национальной экономики. Сегодня России необходима новая индустриализация, точнее неоиндустриализация, которая понимается как качественные изменения в экономике, трансформация производительных сил, переход на цифровые технологии, создание современной инфраструктуры, достижение качественно новый уровней образования и медицинского обслуживания. Инновационная деятельность должна ориентироваться на удовлетворение определенных общественных потребностей, но вместе с тем она является одним из инструментов повышения эффективности использования ресурсов, продуктивности компаний и экономики в целом.

К сожалению, в настоящее время риторика власти подчас далека от реальных условий жизни в нашей стране и условий для ведения бизнеса, экономическая политика не является последовательной, «правила игры» и законодательство часто изменяются, а продвижение к целям многократно сводилось на нет из-за политических разворотов. Контроль над деятельностью чиновников и управленцев осуществляется недостаточно эффективно, в основном за текущим функционалом, что часто приводит к тому, что долгосрочными проектами никто не интересуется и многие из них откладываются до лучших времен, и в конце концов не претворять в жизнь. Все это никак не способствует тому, чтобы чиновники трудились более результативно и принимали рациональные и обоснованные решения. Не случайно Россия по индексу свободы от коррупции занимает 132 место в мире [1]. Значимость чиновника в современной России во многом определяется количеством подчиненных ему людей, и поэтому он стремится к увеличению документооборота, всевозможным согласованиям, визированиям и укреплению своего положения. А это приводит к тому, что большинство проводимых в стране реформ затягиваются, не дают нужных результатов и способствуют расширению командных и административно-бюрократических методов управления, а о расширении самоуправления на местах, что характерно для современных демократических стран, пока только идут разговоры и намерения.

Высокая доля государства в экономике способствует регулярным просчетам в различных отраслях народного хозяйства и социальной жизни, а бюрократизация власти уменьшает их зависимость управленцев от мнения жителей страны и демократических институтов. Начиная с начала 2000-ых годов государство последовательно наращивало свою роль во всех сферах экономики: занимая преобладающие позиции в сырьевых секторах, создавая многочисленные 
госкорпорации и институты развития, усиливая надзорные и контрольные функции и структуры. По оценкам специалистов РАНХиГС, доля государства в создании ВВП выросла с 31\% в 2000 году почти до 50\% [2]. При этом анализ показывает, что эффективность государственного сектора в целом ниже, чем частного, и нет особых перспектив изменения этой ситуации. А еще это ведет к увеличению государственных расходов на содержание аппарата управления. В целом, при сокращении общей численности занятого населения страны наблюдается систематическое увеличение количества чиновников, зарплаты которых существенно выше, чем средние по стране.

Известно, что политика высокого налогообложения существенно тормозит экономическое развитие страны, что и наблюдается в современной России. Налоговая система не стимулирует внедрению инновационных разработок, не оказывает содействия формированию инновационного малого и среднего бизнеса, не поощряет граждан зарабатывать дополнительные средства, и не ведет к сокращению огромного разрыва между богатыми и бедными. За последние годы в России доля среднего класса (наиболее демократической и передовой части общества) уменьшилась с $20 \%$ населения до $15 \%$ [3,c.18]. Более реалистичное представление об условиях для бизнеса в России дают рейтинги Всемирного экономического форума, в которых наша страна занимает 73-е место по бремени госрегулирования, 92-е по независимости судебной системы и 112-е по защищенности прав собственности [2]. Такие показатели несовместимы с поставленной задачей увеличения темпов экономического роста, и неудивительно, что прогнозные показатели крайне неутешительны для будущего экономического развития. К сожалению, в настоящее время в РФ пока только ведутся разговоры о социально-ориентированной экономике, наибольшие льготы от современной налоговой политики получают сверхбогатые и некоторые госкорпорации.

Трудно не согласиться со старшим научным сотрудником экономического факультета МГУ с Т.Н. Юдиной, что в «настоящее время хозяйственная практика и современная фундаментальная экономическая наука явно расходятся между собой» [4,с. 76]. Несмотря на все уверения правительства в 2018 г. мы так и не перешли к устойчивому экономическому росту. Причем при значительном сокращении розничного товарооборота и реальных доходов населения, особенно регионов. Негативно на данный процесс влияет и малая роль на местах гражданского общества, например, жители не могут контролировать качество товаров, услуг, необоснованный рост цен.

В настоящее время развитию российской инновационной системы мешает отсутствие механизмов синхронизации, сбалансированности различных аспектов инновационного развития региона, недостаточно развитая транспортно-дорожная инфраструктура, недостаточный объем затрат предпринимательского сектора на исследования и разработки, слабая координация инновационных проектов с соседними областями и зарубежными государствами. Здесь нужна «индустриализация с новым содержанием с учетом нового контекста инноватизации в новых условиях современности» [5,с.154]. Особо следует подчеркнуть необходимость использования цифровых решений в деятельности хозяйственных субъектов. «Фактически многие сферы человеческой жизнедеятельности в той или иной мере изменяются посредством открытия и развития ИКТ» [6,c.166].

Сегодня необходимо совмещение действенных рыночных механизмов хозяйствования с благоприятным предпринимательским и инвестиционным климатом, существование демократического правового государства, которое создает необходимые условия, как достойной жизни и самореализации любого гражданина, так и для ведения малого и среднего предпринимательства. В связи с этим, по мнению с А.Ю. Чепуренко [7], необходимо фокусироваться на стимулировании роста числа новых частных фирм за счет снижения барьеров, создавать среду, в которой предприниматели и небольшие фирмы смогут процветать, а власти должны их стимулировать к этому. 
Особо следует подчеркнуть необходимость приоритетного развития несырьевого экспорта и усиления государственной поддержки таких компанийэкспортеров. Также, как в США и Китае необходимо создать различные полезные сервисы для экспортеров, с помощью которых легко можно найти дистрибьютеров, оптовиков и трейдеров [8]. Представители российских компаний считают, что главные сложности для экспорта - это трудности в поисках партнеров за рубежом, а также значительные трудности с получением лицензий и сертификатов. Эксперты в области экспорта считают, что в России просто необходимо создать электронную базу с данными обо всех компаниях, которые экспортируют свои товары, и самое главное, государство должно оказывать всестороннюю поддержку отечественным компаниямэкспортерам за границей и максимально упрощать бюрократические процедуры [8].

Таким образом, государству совместно с бизнесом необходимо произвести новую индустриализацию всей экономики, с большей концентрацией ресурсов на наиболее значимых направлениях. Основой же институциональных изменений доли стать государственная инновационная стратегия, последовательно проводимая в жизнь и активная научно-техническая политика, нацеленная на создание и внедрение передовых технологий на основе результатов НИОКР прорывного характера. Все вышеперечисленные меры приведут к восстановлению устойчивого экономического роста, повышению доверия граждан к органам власти, обеспечению социальной и политической стабильности.

$$
* * *
$$

1. Corruption Perceptions Index 2014 / Beddow R.Transperency International. 2015. Режим доступа: https:// www.transparency.org/cpi2014 (дата обращения 11.09.2018).

2. Пируэт Грефа: что еще может спасти российскую экономику / Евсей Гурвич. 3 октября 2019. Режим доступа https:/www.forbes.ru/finansy-i-investicii/384391-piruet-grefa-chto-eshche-mozhetspasti-rossiyskuyu-ekonomiku (дата обращения 19.10.2019).

3. Гринберг Р.С. Экономика мира и России: тренды, шансы, риски/ / Экономическое Возрождение России. 2017. № 1(51). С.17-21.

4. Юдина Т.Н. Конституирующие основы фундаментальной экономической науки: философскохозяйственный взгляд.// Философия хозяйства. 2016. № 6(108). С.75-92.

5. Чжан Ч., Юдина Т.Н. Реиндустриализация промышленной базы Северо-Восточного Китая в XIII пятилетке.// Философия хозяйства. 2017. № 6.С. 146-158.

6. Юдина Т.Н. Цифровизация в контексте сопряженности Евразийского экономического союза и экономического пояса Шелкового пути.// Философия хозяйства. 2016. №4. С.161-171.

7. Чепуренко А.Ю. Совмещая универсальные концепции с национальной спецификой: поддержка малого и среднего предпринимательства.// Вопросы государственного и муниципального управления. 2017.№1. С.7-30.

8. Вот почему Россия не может повторить экономический успех Китая и США. Режим доступа https://zen.yandex.ru/media/slovami/vot-pochemu-rossiia-ne-mojet-povtorit-ekonomicheskii-uspehkitaia-i-ssha-5db1eb0f2f1e4400ae174367 (дата обращения 27.10.2019).

\section{Бексултанова А.И. \\ Становление инфраструктурных центров вузовской науки}

ФГБОУ ВО «Чеченский государственный университет» (Россия, Грозный)

doi: $10.18411 / \mathrm{lj}-10-2019-166$

idsp: ljournal-10-2019-166

\section{Аннотация}

При становлении и развитии национальной инновационный системы актуальной задачей является разработка механизма внедрения вузовской науки в национальную инновационную систему. По мнению автора статьи одной из наиболее эффективных форм действия данного механизма является образовательный кластер.

Ключевые слова: вузовская наука, образование, наука, реформирование 